Georgetown University Law Center

Scholarship @ GEORGETOWN LAW

2014

\title{
Virus Sharing, Genetic Sequencing, and Global Health Security
}

Lawrence O. Gostin

Georgetown University Law Center, gostin@law.georgetown.edu

Alexandra Phelan

Georgetown University Law Center, alp81@georgetown.edu

Michael A. Stoto

Georgetown University, stotom@georgetown.edu

John D. Kraemer

Georgetown University Law Center, jdk32@law.georgetown.edu

K. Srinath Reddy

Public Health Foundation of India, ksrinath.reddy@phfi.org

http://www.sciencemag.org/content/345/6202/1295.short

This paper can be downloaded free of charge from:

https://scholarship.law.georgetown.edu/facpub/1375

http://ssrn.com/abstract=2497482

Science, September 2014, at 1295-1296

This open-access article is brought to you by the Georgetown Law Library. Posted with permission of the author. Follow this and additional works at: https://scholarship.law.georgetown.edu/facpub

Part of the Health Law and Policy Commons, Health Policy Commons, Influenza Humans Commons, Influenza Virus Vaccines Commons, International Law Commons, International Public Health Commons, Public Policy

Commons, and the Virus Diseases Commons 


\title{
Virus sharing, genetic sequencing, and global health security
}

\author{
Lawrence O. Gostin, ${ }^{1}$ Alexandra Phelan, ${ }^{1}$ Michael A. Stoto, ${ }^{2}$ \\ John D. Kraemer, ${ }^{1,2}$ K. Srinath Reddy ${ }^{3}$
}

This Perspective focuses on the future of the Pandemic Influenza Preparedness (PIP) Framework, which was initially established to promote the fair sharing of public health-related pandemic influenza samples between countries. We examine the changes that need to be made to address the growing likelihood that genetic sequence data might be shared instead of physical virus samples, as well as the need to expand the PIP framework's scope and to improve its fairness.

T

he Pandemic Influenza Preparedness (PIP) Framework (1) was a milestone agreement in promoting international sharing of biological samples to develop vaccines, while ensuring that poorer countries would have access to those vaccines. Now genetic sequencing data (GSD) can allow scientists to develop synthetic viruses rapidly for product development. Electronic transfer of GSD could enable wider access to researchers to innovate and share findings, speeding development of life-saving technologies in a time-sensitive global emergency. But access to GSD may also have major implications for biosecurity, biosafety, and intellectual property (IP). By rendering physical transfer of viruses antiquated, GSD may also undermine the effectiveness of the PIP Framework itself, with disproportionate impacts on poorer countries.

In December 2006, Indonesia challenged the fairness of the global preparedness system by refusing to share samples of avian influenza $\mathrm{A}$ (H5N1). Concerned that wealthier countries would gain disproportionate access to vaccines while creating cost barriers for others, Indonesia invoked sovereign ownership of a virus isolated in its territory. The government claimed that the Convention on Biological Diversity prevents exploitation of its "biological and genetic resources," including novel pathogens (2). Indonesia's decisionsupported by many low- and middle-income countries-risked significantly impeding the capacity to monitor and respond to novel influenzas.

It took more than 4 years, but the World Health Organization (WHO) was able to broker the PIP Framework, finalized in May 2011 (Fig. 1). It used a novel strategy to advance global justice by affording more equitable access to the benefits of research. Rather than having governments commit to providing a share of their vaccine stockpiles with lower-income countries in exchange for access to biological samples, the PIP Framework created legally enforceable contractual obligations on participating private and academic partners that are involved in the manufacture of vaccines to make vaccines available to poorer countries.

\footnotetext{
${ }^{1} \mathrm{O}$ 'Neill Institute for National and Global Health Law, Georgetown University Law Center, Washington, DC 20001, USA.

${ }^{2}$ Department of Health Systems Administration, Georgetown University, Washington, DC 20057, USA. ${ }^{3}$ President, Public Health Foundation of India, New Delhi 110070, India.
}

*Corresponding author. E-mail: gostin@law.georgetown.edu

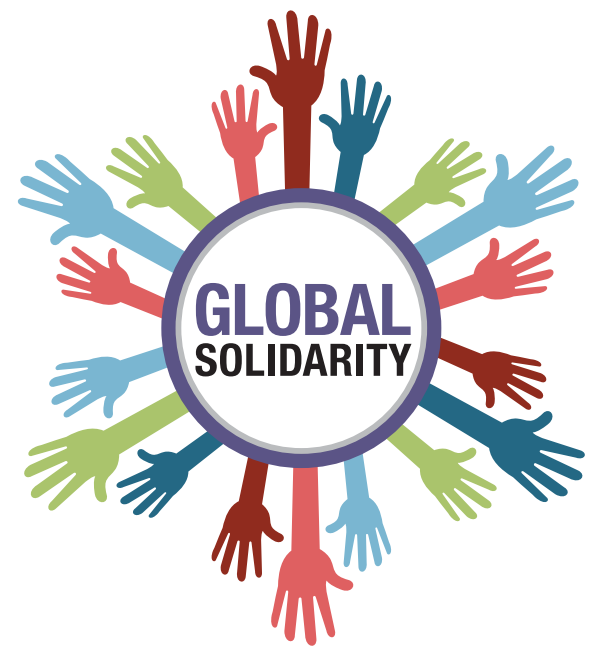

Fig. 1. By sharing influenza viruses with human pandemic potential and building financial and research partnerships, countries can unite to widen access to vaccines.

Although it has the potential to be transformative, the PIP Framework leaves fundamental gaps in health security and in equity.

\section{Gaps in equity, research, and security}

The dynamics behind the PIP Framework were unusual because Indonesia had something to leverage-virus samples critical to the functioning of the global public health system (Fig. 2). The agreement changed an unfair status quo, whereby lower-income countries shared viruses, while relying on ad hoc "charitable" donations of vaccines. For example, during the 2009 influenza (A) H1N1 pandemic, vaccine donation pledges often were not fulfilled until high-income countries had protected their domestic populations (3). In exchange for access to biological materials, the PIP Framework requires researchers and manufacturers to fulfill contractual obligations, such as providing an agreed percentage of vaccines, diagnostics, or pharmaceuticals to the WHO stockpile or granting developing countries "fair and reasonable" or royalty-free licenses to manufacture such products.

In addition to potential limitations in light of GSD discussed below, the PIP Framework is limited in scope as it applies only to influenza vi- ruses with pandemic potential. Seasonal influenza viruses are excluded, as are noninfluenza pathogens irrespective of their pandemic potential. In a globalized world, with myriad emerging infections, the framework's narrow scope excludes the vast majority of future threats. The ownership and sharing of the Middle East respiratory syndrome coronavirus (MERS-CoV), for example, has been controversial, with Saudi Arabian officials circumspect about global cooperation (4). Countries lack the leverage to withhold pathogens already in wide circulation, such as HIV, because scientists can acquire samples from multiple sources.

\section{Gaps in global governance}

The private sector's incentive to participate is its commercial need for viral samples to develop pandemic influenza vaccines. But in May 2013, scientists demonstrated that GSD could be used to rapidly develop synthetic viruses for product development (5). If pharmaceutical researchers no longer require access to biological materials to develop products, private sector cooperation in the framework could decline.

The PIP Framework defines "biological materials" as influenza viruses with human pandemic potential, including extracted RNA and cDNA, which appears to exclude GSD. Although the framework also defines genetic sequences, the framework's sharing and benefits scheme does not explicitly apply to GSD. Noting that some countries treat the publication of pathogen sequencing data as highly sensitive, the PIP Framework left for the future the handling of GSD-which suggests that WHO member states and stakeholders failed to agree during the negotiations.

The omission of GSD in the PIP Framework's sharing and benefits scheme is out of step with global preferences for the inclusion of genetic information of global health importance in public domain or open access databases, to increase transparency and to advance social justice. The National Institutes of Health's genetic sequencing database GenBank, for example, offers an annotated collection of publicly available DNA sequences, which enables data exchange. Similarly, the Global Initiative on Sharing All Influenza Data (GISAID) platform promotes sharing influenzatype virus sequences. Although these sequences are publicly accessible, researchers must acknowledge the originating laboratories that contributed data to the GISAID platform and ensure fair use of research findings.

\section{Biosafety and biosecurity}

Biosafety refers to the maintenance of safe conditions in biological research to prevent inadvertent escape of hazardous materials that could harm workers, persons outside the laboratory, or the environment. Unlike physical virus sharing, sequencing data are not inherently hazardous, and sharing information instead of physical samples mitigates the risk of inadvertent release of the infectious agent by limiting access to biological agents.

Biosecurity refers to the precautions taken to protect against the spread of harmful biological substances. This includes pathogens of dual-use 


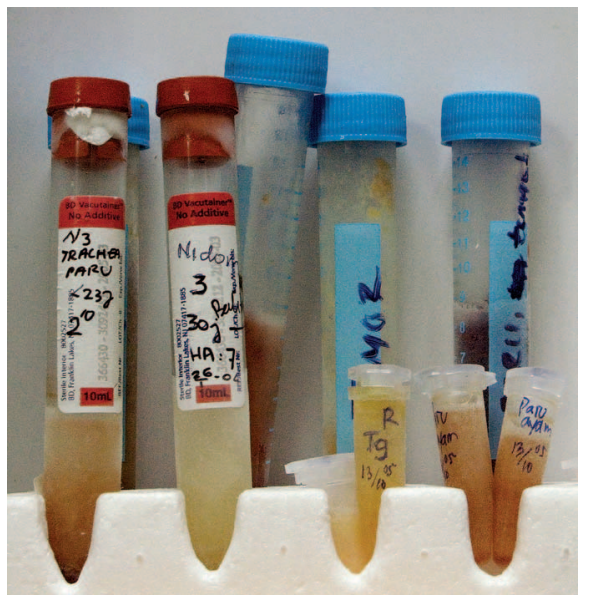

Fig. 2. Bird flu in Indonesia: freewheeling toward a pandemic. Biological samples (poultry and pigs) for the detection of $\mathrm{H} 5 \mathrm{~N} 1$ virus at the Virology Laboratory Control Center for Tropical Diseases, University of Surabaya, Java. [CORBIS]

research of concern: life sciences research intended for benefit, but which could be misapplied to do harm, such as through bioterrorism. GSD pose unique biosecurity threats because of their potential for broad global dissemination, which results in insecure laboratories or potential terrorists gaining access. At present, the technical sophistication to use genetic sequencing to create a hazardous agent is beyond the expertise of most scientists, and presumably more so of potential bioterrorists. However, the future risk of recreating a lethal virus cannot be discounted, especially as sequencing data become more widely available on the Internet and through scientific publications (6).

Governments could also use export controls to limit sharing of biological materials or GSD. Many countries require a license to export particularly dangerous pathogens, although export licenses are routinely granted for legitimate scientific research. In rare instances, governments have used export controls to limit dissemination of pathogen GSD-as when the Netherlands restricted publication of enhanced H5N1 influenza research-but this is uncommon for unclassified basic science research (7).

\section{Intellectual property}

Claiming IP rights is highly polarizing because it can make essential medicines and vaccines less affordable. To ensure greater fairness, the PIP Framework imposes contractual prohibitions on IP asserted over biological materials transferred within the WHO Global Influenza Surveillance and Response System. The framework's intent is to prevent recipients of biological materials from exploiting a global resource for their own financial benefit. Although a contract between the $\mathrm{WHO}$ and a recipient may not invalidate IP rights afforded in the researcher's home country, it could permit a lawsuit for breach of contract.

Countries have varying laws as to whether naturally occurring biological samples are patentable. A biological sample, such as a virus sample, would likely fall under the scope of "naturally occurring substances" and thus not be patentable as defined by the World Intellectual Property Organization (8). GSD, however, entail additional intellectual steps from simply isolating the virus. Still, it is conceivable that GSD might be deemed a nonpatentable "naturally occurring substance" in major jurisdictions such as the United States (9).

Although the PIP Framework does not displace the IP regimes of domestic jurisdictions, extending the framework to cover GSD would contractually prohibit unauthorized assertions of property rights over GSD, similar to biological materials. Such an expansion of coverage would further the framework's objectives of social justice, while encouraging open access to GSD.

\section{Global health governance}

The private sector (e.g., pharmaceuticals, forprofit health care providers, food, alcohol, and tobacco) has powerful effects on the public's health, security, and safety. Yet, the WHO finds it hard to govern these and other nonstate actors. When it does mobilize multiple stakeholders, the norms set are usually voluntary, such as through action plans or codes of practice. A perennial weakness of international agreements is their inability to assure compliance. The PIP Framework not only includes the private sector in global health negotiations but also creatively applies civil contract law to enforce the agreement-a model for future global health diplomacy.

Thus, despite its weaknesses and omissions, the PIP Framework offers an innovative template for future global health agreements. The framework brought together the WHO secretariat, member states, and the pharmaceutical industry in an unprecedented way. Traditional international law creates state obligations, but rarely, if ever, binds the private sector. The PIP Framework-which is not in the form of a treaty-uniquely creates legally enforceable contractual obligations on participating private and academic partners that manufacture vaccines, antivirals, or diagnostics. Consequently, as a method of global health governance, the framework has the potential to be transformative.

\section{Filling the gaps in the PIP framework}

A recent WHO review of the PIP Framework offered an opportunity to close major gaps but also revealed the text's rigidity in adapting to rapid scientific progress (10). GSD fundamentally change the paradigm within which the PIP Framework operates, potentially rendering the framework less effective.

In the short run, it would be best simply to interpret the framework to include GSD as biological materials. Keeping GSD under the umbrella of a global agreement would facilitate tracking sequencing data, while holding users accountable-facilitating socially productive research, while limiting harmful use. A tracking system need not be burdensome or restrict the free flow of scientific information. A simple registration system that monitors who has downloaded GSD would help ensure that recipients abide by global research norms and could be incorporated into existing databases such as the GISAID platform. Moreover, allowing free exchange of GSD without enforcing the obligations owed to the donating country essentially unravels the PIP Framework "bargain" after the fact, undermining both the framework's legitimacy and the WHO's credibility to negotiate future agreements.

In the long run, the gaps in the framework that we describe open an opportunity to resolve other existing weaknesses by revising the text. A revised framework should be driven by norms of equity and shared global vulnerability, with the vital goals of open access to research materials, accessible license agreements, and more rapid development of therapeutic countermeasures. Note that fairness requires that lifesaving vaccines and pharmaceuticals, as well as the results of research, are equitably distributed in low- and middle-income countries that lack the ability to purchase products in the market or produce them domestically.

Further, the sharing of biological materials, as well as GSD, should be extended beyond influenza to all other hazardous pathogens with pandemic potential, such as novel coronaviruses. If the intent of the framework is to facilitate research and speed the development of vaccines and antiviral medications, a narrow scope of application diminishes the effectiveness of global health governance (11). The use of GSD in product development could prove to be a remarkable achievement. However, this and other scientific advancements need to be harnessed to safeguard populations worldwide not simply countries that can afford the products derived from innovative research. Global health security is vital but so, too, is equitable access. Not only will this ensure a more secure and healthy world, but also a more just world, for humanity.

\section{REFERENCES AND NOTES}

1. WHO, Pandemic Influenza Preparedness Framework for the sharing of influenza viruses and access to vaccines and other benefits ("PIP Framework"), adopted in "Report by the OpenEnded Working Group of Member States on Pandemic Influenza Preparedness: Sharing of influenza viruses and access to vaccines and other benefits" (WHO Doc A64/8, WHO, Geneva, 2011).

2. E. R. Sedyaningsih, S. Isfandari, T. Soendoro, S. F. Supari, Ann. Acad. Med Singapore 37, 482-487 (2008)

3. D. P. Fidler, PLOS Med. 7, e1000247 (2010).

4. D. P. Fidler, Foreign Aff., 7 June 2013; www.foreignaffairs.com/articles/ 139443/david-p-fidler/who-owns-mers.

5. P. R. Dormitzer et al., Sci. Transl. Med. 5, 85ra68 (2013)

6. J. D. Kraemer, L. O. Gostin, Science 335, 1047-1049 (2012).

7. M. Enserink, Science Insider, 25 September 2013; http://news.sciencemag.org/health/2013/09/flu-researcher ron-fouchier-loses-legal-fight-over-h5n1-studies.

8. World Intellectual Property Organization, "Working paper: Patent issues related to influenza viruses and their genes" (WIPO, Geneva, 2007); www.wipo.int/export/sites/www/ policy/en/global_health/pdf/influenza.pdf.

9. Association for Molecular Pathology v. Myriad Genetics, 569 U.S. (2013)

10. Technical Expert Working Group on Genetic Sequence Data, "Final Report of the Technical Expert Working Group (TEWG) on Genetic Sequence Data to the PIP Advisory Group" (WHO, Geneva, 2014); www.who.int/influenza/pip/advisory group/en/.

11. L. O. Gostin, Global Health Law (Harvard Univ. Press, Cambridge, MA, 2014).

\section{ACKNOWLEDGMENTS}

Disclosures: L.O.G. was a member of the WHO Technical Expert Working Group (TEWG) on Genetic Sequence Data to the PIP Advisory Group and is the Director of the WHO Collaborating Center on Public Health Law and Human Rights.

10.1126/science.1257622 